\title{
Efficacy of puffer fish (Takifugu rubripes) sauce in reducing hydroxyl radical damage to DNA assessed using the apurinic/apyrimidinic site method
}

\author{
KAZUKI HARADA ${ }^{1}$, YOSHIO MAKINO ${ }^{2}$, TOMIO YAMAUCHI ${ }^{3}$, NAMI FUKUDA ${ }^{1}$, MIKI TAMARU ${ }^{1}$, \\ YASUE OKUBO $^{1}$, TOSHIMICHI MAEDA ${ }^{1}$, YUTAKA FUKUDA ${ }^{1}$ and TSUNEO SHIBA ${ }^{4}$ \\ ${ }^{1}$ Laboratory of Marine Resource Processing, Department of Food Science and Technology, National Fisheries University, \\ Independent Administrative Institution, The Ministry of Agriculture, Forestry and Fisheries of Japan, 2-7-1 \\ Nagata-Honmachi, Shimonoseki-shi, Yamaguchi 759-6595; ${ }^{2}$ Laboratory of Bioprocess Engineering, \\ Department of Biological and Environmental Engineering, Graduate School of Agricultural \\ and Life Sciences, The University of Tokyo, 1-1-1 Yayoi, Bunkyo-ku, Tokyo 113-8657; \\ ${ }^{3}$ School of Materials Science, Japan Advanced Institute of Science and Technology (JAIST), \\ 1-1 Asahidai, Nomi-shi, Ishikawa 923-1292; ${ }^{4}$ Laboratory of Food Safety, Department of Food \\ Science and Technology, National Fisheries University, Independent Administrative \\ Institution, The Ministry of Agriculture, Forestry and Fisheries of Japan, Japan
}

Received January 9, 2007; Accepted February 20, 2007

\begin{abstract}
Apurinic/apyrimidinic (AP) sites are frequently observed DNA lesions when cells are exposed to hydroxyl radicals. We developed a new method for measurement of the antioxidative activity of foods using the occurrence frequency of AP sites on DNA. Combined with the electron spin resonance (ESR) method as a standard method, we examined whether fish and soy sauces including puffer fish [Takifugu rubripes (Temminck et Schlegel)] sauce could protect DNA from damage caused by hydroxyl radicals. The results showed that the ratios of DNA protection by puffer fish sauce, salmon fish sauce, sandfish fish sauce (Shottsuru), colorless soy sauce, squid fish sauce (Ishiru), dark color soy sauce and light color soy sauce were 68.9, 67.0, 60.1, 49.7, $34.1,28.2$ and $-4.4 \%$, respectively. Puffer, salmon, and sandfish fish sauces showed high ratios of DNA protection against hydroxyl radicals. On the other hand, $\mathrm{IC}_{50}$ values of hydroxyl radical scavenging of the puffer, salmon, sandfish, squid fish sauces and colorless, dark and light color soy sauces
\end{abstract}

Correspondence to: Dr Kazuki Harada, Laboratory of Marine Resource Processing, Department of Food Science and Technology, National Fisheries University, Independent Administrative Institution, The Ministry of Agriculture, Forestry and Fisheries of Japan, 2-7-1 Nagata-Honmachi, Shimonoseki-shi, Yamaguchi 7596595, Japan

E-mail: kazuki@fish-u.ac.jp

Key words: apurinic/apyrimidinic site, hydroxyl radical, DNA protection, puffer fish, fish sauce were $0.20,0.09,4.16,0.26 \%$ and $0.28,0.14$ and $0.18 \%$, respectively. Though the puffer fish sauce exhibited the highest level of DNA protection among the examined samples and a high hydroxyl radical scavenging capability, a correlation between the radical scavenging capability and DNA protection against hydroxyl radicals among the examined fish and soy sauces was not found.

\section{Introduction}

Radicals are molecules that contain one or more unpaired electrons. Oxidative damage caused by oxygen-derived species, such as superoxide anion $\left(\mathrm{O}_{2}^{-}\right)$and $\mathrm{H}_{2} \mathrm{O}_{2}$, has been implicated in the initiation of cancer (1), and foods are implicated in $30 \%$ of the cases. There is considerable interest in the possibility that $\mathrm{O}_{2}^{-}$and $\mathrm{H}_{2} \mathrm{O}_{2}$ exert their toxicity by being converted into the highly reactive hydroxyl radical $\bullet \mathrm{OH}$ in reactions that require metal ions (2). Therefore, antioxidants in the human diet are of great interest as possible protective agents for reducing oxidative damage, and a wide variety of supplements have been produced as such agents. As well, many researchers have sought radical scavengers from food products (3-6).

On the other hand, fish sauces are traditional Japanese and Asian fermented food seasonings. In Japan, 'Shottsuru' is made from sandfish, 'Ishiru' is made from squid and 'Ikanago Shoyu' is made from sand lance fish. Also, 'Jeotgal' in Korea, 'Patis' in the Philippines, 'Nam plaa' in Thailand, 'Nouc mam' in Vietnam and 'Yuiru' in China are famous fish sauces from East and Southeast Asia. We have examined the high antioxidative activities of seafoods including fish sauces by examining the peroxyl and hydroxyl radical scavenging capability by using the chemiluminescence and 
the electron spin resonance (ESR) methods (7-10). However these activities have not yet been examined based on a biological system.

Tamm et al (11) found for the first time that acid treatment of DNA protonated the N-glycosidic bonds of purines in purified DNA, resulting in the hydrolysis of purines from the pentose sugar without breaking the phosphodiester backbone directly. Greer and Zamenhof (12) reported that purine bases are also slowly released from DNA during incubation at a neutral $\mathrm{pH}$ and high temperature. Based on the determined rate constant for depurination of Bacillus subtilis DNA of $3 \times 10^{-11} \mathrm{sec}^{-1}$ per nucleotide at $37^{\circ} \mathrm{C}$ and $\mathrm{pH} \mathrm{7.4,} \mathrm{Lindahl} \mathrm{and}$ Nyberg (13) considered that depurination of DNA may occur at a physiologically significant rate under in vivo conditions. It was reported that the number of depurination sites on DNA in microbial cells of $B$. subtilis $(14,15)$ and the radioresistant bacterium Deinococcus radiodurans (16) increased with a marked decrease in $\mathrm{pH}$ value and a marked increase in temperature. In this study, we found the apurinic/apyrimidinic (AP) site phenomenon as one of the DNA lesions frequently observed when the extracted DNA is exposed to hydroxyl radicals generated from the Fenton's reaction.

We developed a new method for measurement of antioxidative activity using the occurrence frequency of AP sites on DNA, and we examined whether some seafood, especially fish and soy sauces could protect the DNA from hydroxyl radical damage in vitro.

\section{Materials and methods}

Samples of fish and soy sauces. The puffer fish [Takifugu rubripes (Temminck et Schlegel)] sauce was made in our laboratory using the meat, skin and bones without the internal organs containing the poison, i.e. tetrodotoxin. The puffer fish materials were added to soybean, wheat, soy sauce koji mold, $\mathrm{NaCl}$ and water. These were fermented for $\sim 1$ year at room temperature. As the puffer fish sauce, we used the supernatant of the fermented original sauce mash after heat sterilization. Salmon fish sauce 3, sandfish fish sauce (Shottsuru) and squid fish sauce 1 (Ishiru) were described in our previous study (8), and extremely dark color soy sauce 2 , light color soy sauce 4 and colorless soy sauce 2 were similarly described in our previous study (17).

Chemicals. Hydrogen peroxide $\left(\mathrm{H}_{2} \mathrm{O}_{2}\right)$ was obtained from Santoku Chemical Industries Co., Ltd. (Tokyo, Japan); iron (II) sulfate heptahydrate $\left(\mathrm{FeSO}_{4} \cdot 7 \mathrm{H}_{2} \mathrm{O}\right)$ was from SigmaAldrich Japan K.K. (Tokyo, Japan); and 5,5-dimethyl-1pyrroline $N$-oxide (DMPO), as a spin trapping reagent, was from Tokyo Kasei Kogyo Co., Ltd. (Tokyo, Japan). Tris(hydroxymethyl)aminomethane and deoxyribonucleic acid (DNA) sodium salt from salmon testes were obtained from Sigma-Aldrich Corporation (St. Louis, MO, USA). Ethylenediamine-N,N,N',N'-tetraacetic acid, disodium salt, dihydrate (EDTA.2Na) and aldehyde reactive probe (ARP; $\mathrm{N}$-aminooxymethylcarbonylhydrazino-D-biotin) solution, horseradish peroxidase (HRP)-streptavidin, ARP-DNA standard solution, DNA binding solution, substrate solution and PBST washing buffer (phosphate-buffered saline with $0.05 \%$ Tween-20, pH 7.4) from Dojindo Laboratories
(Kamimashiki-Gun, Kumamoto, Japan) were used as a DNA damage quantification kit. Hydrochloric acid $(\mathrm{HCl})$ and sulfuric acid $\left(\mathrm{H}_{2} \mathrm{SO}_{4}\right)$ were from Wako Pure Chemical Industries, Ltd. (Osaka, Japan).

Electron spin resonance (ESR) experiment procedure. The electron spin resonance (ESR) method was described previously (18) and explained as follows. Hydroxyl radicals were generated by the Fenton's reaction. First, $50 \mu 1$ of a $1.0-\mathrm{mM} \mathrm{FeSO}_{4}$ solution was added to $20 \mu \mathrm{l}$ of a $90-\mathrm{mM}$ DMPO solution as a spin trapping reagent, and this mixing solution was further added to $250 \mu 1$ of fish or soy sauce as the sample or to ultra pure water as the control. The ultra pure water was made using the ultrapure water purification system (Milli-Q Jr., Nihon Millipore Kogyo K.K., Yonezawa, Japan). Next, the sample or control solution was added to $50 \mu 1$ of an 8.8- $\mathrm{mM} \mathrm{H}_{2} \mathrm{O}_{2}$ solution to initiate the Fenton's reaction, which occurs as in the following chemical equation: $\mathrm{Fe}^{2+}+\mathrm{H}_{2} \mathrm{O}_{2} \rightarrow$ $\mathrm{Fe}^{3+}+\cdot \mathrm{OH}+\mathrm{OH}^{-}$.

After 1 min of the Fenton's reaction, the hydroxyl radical generation, i.e. spin adduct DMPO-OH• was measured using the ESR spectrometer (JES-FR30, JEOL Ltd., Tokyo, Japan). The ESR measurement conditions were as follows: output, $4 \mathrm{~mW}$ (9.4 GHz); magnetic field, 342.790 5 mT; modulation amplitude, $0.079 \mathrm{mT}$; response time, $0.1 \mathrm{sec}$; sweeping time, $1 \mathrm{~min}$; and amplification ratio, 32-125.

Calculation of the $I C_{50}$ value of hydroxyl radical scavenging. As an indicator of the antioxidative activity, the inhibition of the hydroxyl radical peak in the ESR pattern was measured by the change of the peak height ratio of the sample compared with the inner standard manganese peak height. The lower the peak height ratio, the more inhibition of hydroxyl radical generation occurred. The value $\mathrm{IC}_{50}$ was defined as the concentration of fish or soy sauce reducing the control peak height ratio of ESR to half. First, the antioxidative value was calculated using the following formula: $(\log \mathrm{Io} / \mathrm{I}) \times 100$; Io = peak height ratio of the control; $\mathrm{I}=$ peak height ratio of each concentration of the fish or soy sauce sample.

When the value of this formula reached 30.103 , the I value corresponded to half-inhibition. Next, from the relationship between the antioxidative value and the concentration of the fish or soy sauce, the $\mathrm{IC}_{50}$ value was calculated (18).

Preparation of DNA sample. DNA sodium salt from salmon testes was resolved in TE buffer $(10 \mathrm{mM}$ Tris- $\mathrm{HCl}, 1 \mathrm{mM}$ EDTA.2Na, $\mathrm{pH} 7.5$ ) at the concentration of $1 \mathrm{mg} / \mathrm{ml}$ as the DNA solution. Hydroxyl radical-damaged DNA and antioxidized DNA samples were prepared according to the modified method described previously (19). DNA solution $(300 \mu \mathrm{l})$ in a $1.5-\mathrm{ml}$ microtube was added to $50 \mu \mathrm{l}$ of a $1.0-\mathrm{mM}$ $\mathrm{FeSO}_{4}$ solution, $250 \mu \mathrm{l}$ of fish or soy sauce as the antioxidized DNA sample, or pure water as a positive control, i.e. hydroxyl radical-damaged DNA sample, and immediately incubated at $37^{\circ} \mathrm{C}$ for $5 \mathrm{~min}$ in a water bath (ThemoMax Tm-1, As One Corporation, Osaka, Japan). Next, this mixing DNA solution was added to $50 \mu \mathrm{l}$ of an $8.8-\mathrm{mM} \mathrm{H}_{2} \mathrm{O}_{2}$ solution, and mixed quickly with a micropipette, initiating the Fenton's reaction. As a negative control, the mixing DNA solution 
was added to $50 \mu \mathrm{l}$ of pure water instead of $\mathrm{H}_{2} \mathrm{O}_{2}$ solution. All the solutions were again incubated at $37^{\circ} \mathrm{C}$ at $15 \mathrm{~min}$ in the water bath. These solutions were cooled in ice to be used as each DNA sample.

Preparation of ARP-labeled DNA. ARP (aldehyde reactive probe; N'-aminooxymethylcarbonylhydrazino-D-biotin)labeled DNA solution was prepared according to a modified method described previously $(20,21)$. A $100-\mu 1 / \mathrm{ml}$ concentration solution of each DNA sample was prepared by dilution with TE buffer, and measured at $260 \mathrm{~nm}$ absorbance using an UV-VIS spectrophotometer (UV mini 1240 , Shimadzu Corporation, Kyoto, Japan) with a quartz cuvet of 10- $\mu$ l volume (105.210-QS-1, Hellma GmbH and Co. KG, Müllheim, Germany). Ten microliters of prepared DNA solution was mixed with $10 \mu 1$ of ARP solution in a $1.5-\mathrm{ml}$ microtube. Biotinylation of AP sites on DNA was completed by incubating the mixed solution sample at $37^{\circ} \mathrm{C}$ for $1 \mathrm{~h}$ in the water bath. The incubated mixture was then added with $380 \mu 1$ of TE buffer, and transferred to the $0.5-\mathrm{ml}$ filtration tube Microcon model YM-30 (molecular weight; 30,000, Bedford, MA, USA). The filtration tube was centrifuged at 2,500 x $\mathrm{g}$ for $20 \mathrm{~min}$, and the filtrated solution was discarded. The ARP-labeled DNA on the filter was re-suspended in $400 \mu 1$ of TE buffer with a micropipette, and then centrifuged at $2,500 \mathrm{x} \mathrm{g}$ for $20 \mathrm{~min}$ and the filtrate was discarded. The ARP-labeled DNA was finally prepared in $400 \mu \mathrm{l}$ of TE buffer by serially re-suspending with $200 \mu 1$ of TE buffer, then transferred to a $1.5-\mathrm{ml}$ microtube, and stored at $0-5^{\circ} \mathrm{C}$.

Determination of the number of AP sites in DNA. Ninety microliters of the ARP-labeled DNA solution was diluted with $310 \mu 1$ of TE buffer, and then $60 \mu 1$ of the solution was placed in one well of a 96-well microplate with a U-shaped bottom. The ARP-labeled DNA was adsorbed to the well by mixing with $100 \mu 1$ of a DNA binding solution from a DNA damage quantification kit (Dojindo Laboratories) and incubated overnight at room temperature. After discarding the solution, the well was washed 5 times with $250 \mu 1$ of PBST washing buffer using an auto-miniwasher (BioTec Co., Ltd., Tokyo, Japan). The plate was inverted and tapped on a paper towel several times to remove the solution completely. A $150-\mu 1$ aliquot of horseradish peroxidase (HRP)streptavidin solution, which was diluted 4,000-fold with PBST washing buffer, was added to each well, and the plate was incubated at $37^{\circ} \mathrm{C}$ for $1 \mathrm{~h}$. The reaction solution in the well was discarded and the well was washed with $250 \mu 1$ of PBST washing buffer 5 times, and tapped on a paper towel. One hundred microliters of the substrate solution was added to each well, mixed with a micropipette, and incubated at $37^{\circ} \mathrm{C}$ for $1 \mathrm{~h}$. Fifty microliters of reaction mixture, which developed a blue color at this point, was mixed with $50 \mu \mathrm{l}$ of $1 \mathrm{M}$ sulfuric acid, and changed to yellow. The absorbance was determined at $450 \mathrm{~nm}$ using the multilabel microplate reader Mithras LB940 (Berthold Technologies GmbH and Co. KG). Dual samples were determined for each set of data, and ARP-labeled DNA solution was replaced with TE buffer for the background determination. For the calibration curve, $60 \mu 1$ each of standard $[0,2.5,5,10,20$ and 40 AP sites per $1 \times 10^{5}$ base pairs (bp)] was placed in two wells of the 96-well

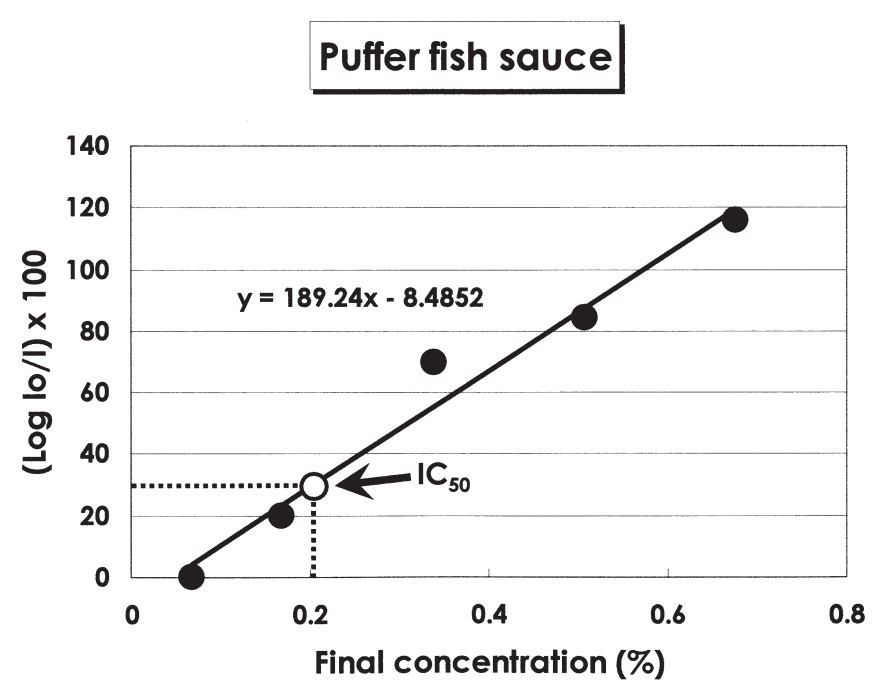

Figure 1. The relationship between the chemiluminescent yield and the final concentration of puffer fish sauce as an example. The antioxidative value was calculated and plotted against the final concentration of this fish sauce.

plate per one concentration sample of the standard solution. We were able to determine 1-40 AP sites per $1 \times 10^{5} \mathrm{bp}$.

Calculation of the ratio of DNA protection. The ratio of DNA protection was defined as the following equation: Ratio of DNA protection $(\%)=[(\mathrm{A}-\mathrm{B})-(\mathrm{C}-\mathrm{B})] \times 100 /(\mathrm{A}-\mathrm{B})=(\mathrm{A}$ - C) x 100/(A - B): A, number of AP sites per 100,000 bp after being exposed to hydroxyl radicals in the Fenton's reaction solution as a control; $\mathrm{B}$, number of AP sites per 100,000 bp without the exposure; and C, number of AP sites per $100,000 \mathrm{bp}$ after the exposure with a fish or soy sauce.

\section{Results}

$I_{50}$ of hydroxyl radical scavenging capability of fish and soy sauces. The $\mathrm{IC}_{50}$ of the sauce was defined, in this experiment, as the dilution level of the sauce product effective in depressing the strength of electron spin resonance (ESR) of hydroxyl radicals by half. This level was calculated from the linear calibration curve obtained between the levels of the depression and the dilution of the sauce products added as a hydroxyl radical scavenger. The antioxidative value of $30.103(\log 2 \mathrm{x}$ 100), which corresponded to half-depression, was calculated to be $0.20 \%$ in the case of puffer fish sauce, as shown in Fig. 1. Similar linear relationships were obtained for the other 7 sauces, and their $\mathrm{IC}_{50}$ values were calculated by the same method.

Quantity of AP sites on DNA damaged by hydroxyl radicals. The quantity of AP sites on DNA damaged by hydroxyl radicals was obtained from the calibration curve using the ARP-DNA standard solution (Fig. 2). From the calibration curve, the number of AP sites produced without exposure to hydroxyl radicals, i.e., spontaneous DNA damage, was calculated to be 9.66 per 100,000 base pairs (bp) and that of DNA exposed to hydroxyl radicals produced by the Fenton's reaction was 42.34 (Fig. 3). 


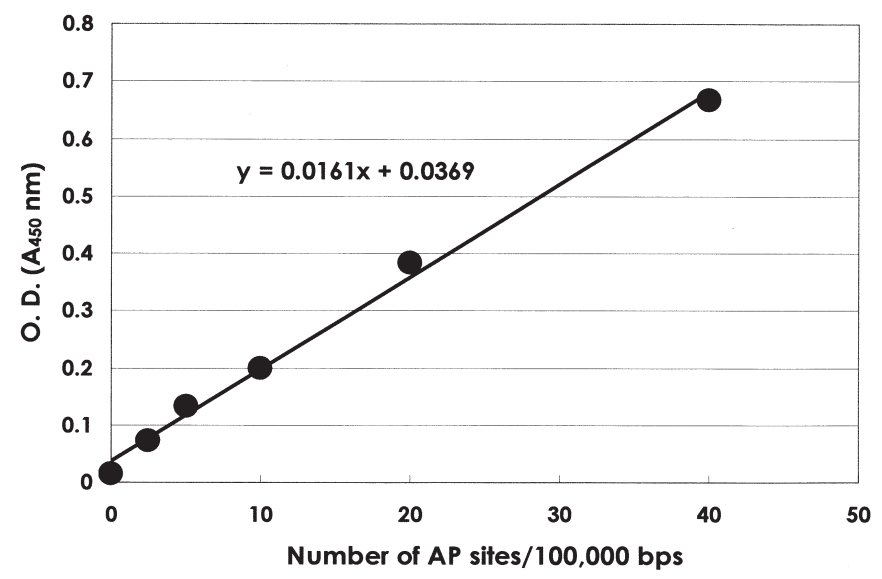

Figure 2. The calibration curve using ARP-DNA standard solution. The vertical axis indicates the optical density at $450 \mathrm{~nm}$; the horizontal line, the number of AP sites per 100,000 bp.

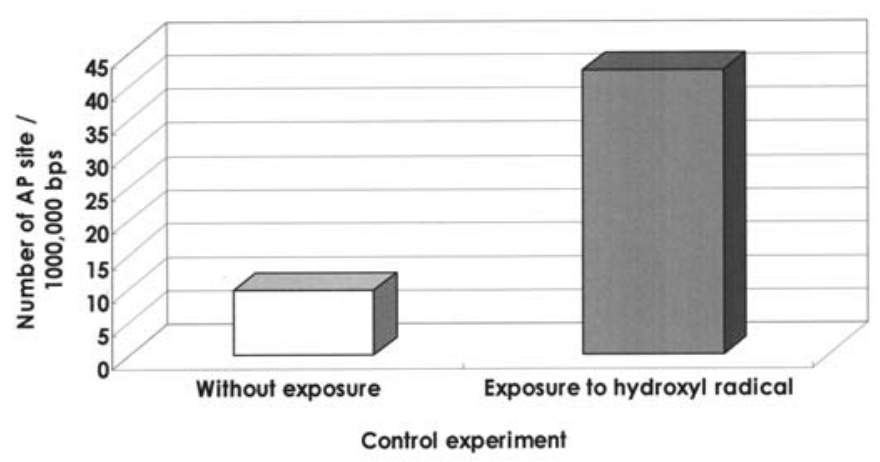

Figure 3. The control experiment indicating the quantity of AP sites for DNA damaged by hydroxyl radicals generated from the Fenton's reaction. The white bar indicates the number of AP sites per 100,000 bp without the exposure to hydroxyl radicals; the gray bar, the number of these sites after exposure to hydroxyl radicals in the Fenton's reaction solution.

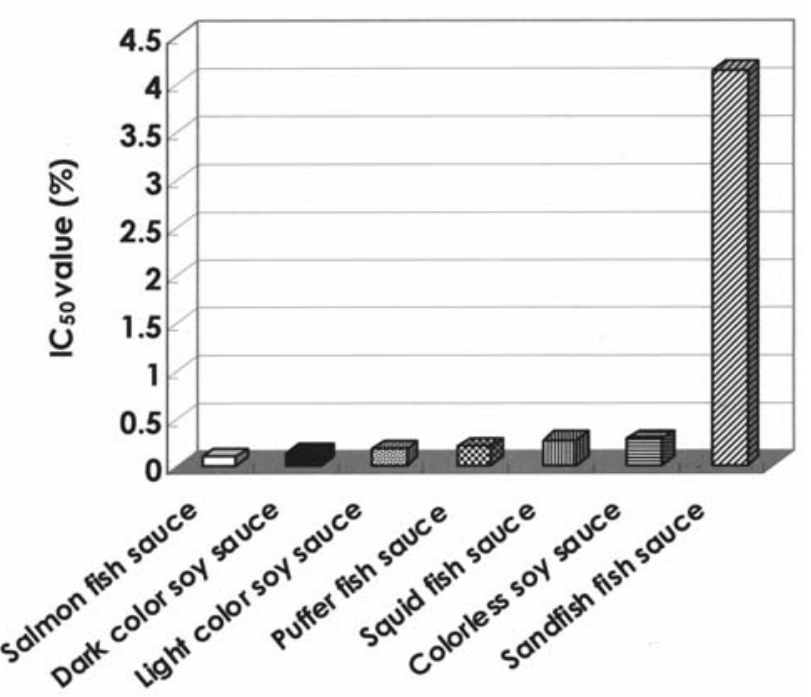

Figure $4 . \mathrm{IC}_{50}$ value $(\%)$ of the hydroxyl radical scavenging capability of each fish and soy sauce using the ESR method. The white bar indicates salmon fish sauce; black bar, the dark color soy sauce; bar with dots, the light color soy sauce; bar with small squares, the puffer fish sauce; bar with vertical stripes, the squid fish sauce; bar with horizontal stripes, the colorless soy sauce; and bar with oblique stripes, the sandfish fish sauce.

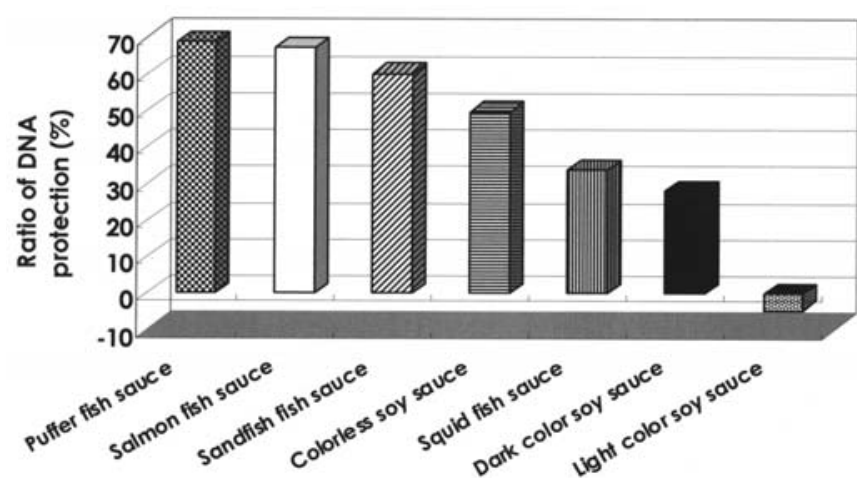

Figure 5. Ratio of DNA protection (\%) against hydroxyl radical damage in the Fenton's reaction solution. Details of the bars are described in the legend of Fig. 4.

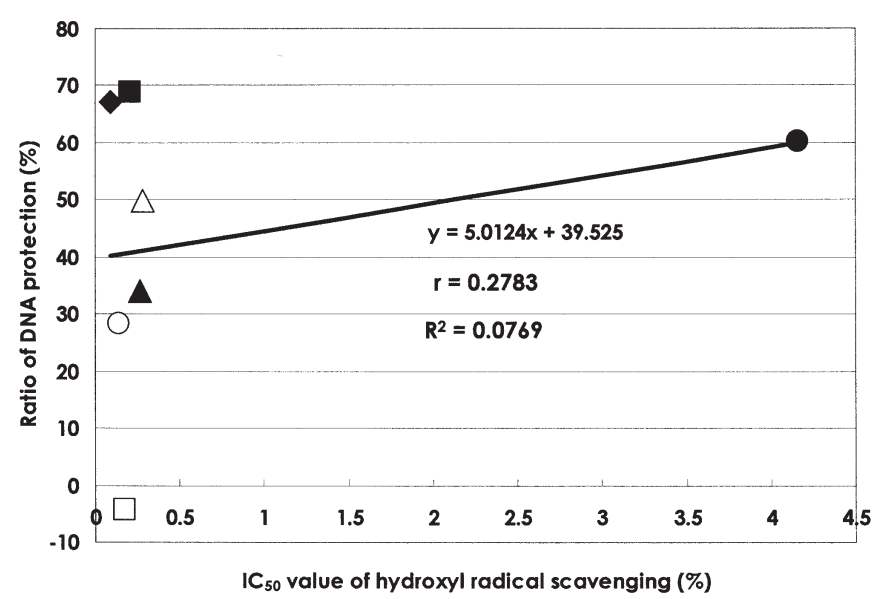

Figure 6. Relationship between the ratio of DNA protection and $\mathrm{IC}_{50}$ value of hydroxyl radical scavenging. Symbols: $\mathbf{a}$ puffer fish sauce, salmon fish sauce, $\bullet$ sandfish fish sauce, $\triangle$ colorless soy sauce, $\Delta$ squid fish sauce, 0 dark color soy sauce, and $\square$ light color soy sauce.

Evaluation of the antioxidative level of fish and soy sauces. The $\mathrm{IC}_{50}$ values were compared among the various fish and soy sauces. The order of the strength of hydroxyl radical scavenging capability is shown in Fig. 4; the lower the height of the bar in the figure the stronger the radical scavenging capability. Based on the data in the figure, salmon fish sauce, dark color soy sauce, light color soy sauce, puffer fish sauce, squid fish sauce (Ishiru) and colorless soy sauce showed high hydroxyl radical scavenging capabilities. The $\mathrm{IC}_{50}$ values of these sauces were $0.09,0.14,0.18,0.20,0.26$ and $0.28 \%$, respectively. On the other hand, sandfish fish sauce (Shottsuru) showed weak antioxidative activity compared with the sauces described above; the $\mathrm{IC}_{50}$ value of this fish sauce was $4.16 \%$.

Evaluation of DNA protection against hydroxyl radicals. The order of the level of the ratio of DNA protection against hydroxyl radicals is shown in Fig. 5. The puffer fish sauce showed the highest ratio of DNA protection, $68.9 \%$. Based on the data in the figure, the ratio of DNA protection of salmon fish sauce, sandfish fish sauce (Shottsuru), colorless soy 
sauce, squid fish sauce (Ishiru), dark color soy sauce and light color soy sauce was $67.0,60.1,49.7,34.1,28.2$, and $-4.4 \%$, respectively. Puffer, salmon and sandfish fish sauces showed high ratios of DNA protection against hydroxyl radicals.

Relationship between the ratio of DNA protection and the $I C_{50}$ value of hydroxyl radical scavenging. The relationship between the ratio of DNA protection and the $\mathrm{IC}_{50}$ value of hydroxyl radical scavenging was examined using correlation coefficient (r), regression line and coefficient of determination $\left(\mathrm{R}^{2}\right)$ (Fig. 6). As a result, the equation of the regression line was $y=5.0124 x+39.525$, the correlation coefficient was 0.2861 and the coefficient of determination was 0.0819 . Therefore, we judged that a mutual relation was absent at $5 \%$ $(\mathrm{p}=0.05)$ of the level of significance.

\section{Discussion}

Apurinic/apyrimidinic (AP) sites are the most common DNA lesions which are spontaneously created by the release of deaminated bases under various physiological conditions (13). Oxidative attack by hydroxyl radicals on the deoxyribose moiety produces a multiplicity of modifications in DNA, namely it leads to the release of free bases from DNA, generating strand breaks with various sugar modifications and simple AP sites. In fact, AP sites are one of the major types of damage generated by hydroxyl radical species. It has been estimated that endogenous reactive oxygen species can result in $\sim 2 \times 10^{5}$ base lesions per cell per day. The biotinylated reagent aldehyde reactive probe (ARP) specifically reacts with the aldehyde group of AP sites, and damage to these biotin-tagged sites can be detected by an ELISA-like assay $(20,21)$.

The AP site DNA method has been used in various research fields, namely DNA damage and its repair in bacteria, yeast or cell culture, and the protection against acute renal damage using rats and postischemic brain injury (22-26). For example, Monti et al reported the influence of base excision repair defects on the processing of Me-lex (a methyl sulfonate ester appended to a neutral N-methylpyrrolecarboxamide-based dipeptide) lesions on plasmid DNA that harbors the p53 cDNA as a target in yeast using the AP site DNA method (22). Also, using this method, Satoh et al reported that edarabone (3-methyl-1-phenyl-pyrazolin-5-one) as a novel free radical scavenger protected against cisplatininduced acute renal damage in male Wistar rats (25). In addition, it was reported, again using this method, that abasic sites, hallmarks of oxidative DNA damage, were significantly increased in DNA from the ischemic brain of folate-deficient animals at early time points after middle cerebral artery occlusion (26).

For the first time, Makino et al tried the AP site DNA method in the field of food antioxidants in 2001 (19). We further developed this method in order to research the antioxidative activity of fish and soy sauce seasonings. In this study, we found that puffer fish sauce and other fish and soy sauces exhibited a high ratio of DNA protection against hydroxyl radicals. However, no relation between the protection against DNA damage by hydroxyl radicals and the hydroxyl radical scavenging capability of fish and soy sauces was observed. Some mechanism, which mediates or depresses the reactivity of the hydroxyl radicals to DNA molecules, may be present. The mechanism seems to affect the efficiency of the antioxidative activity of the sauce products. Therefore, we conclude that the antioxidative activity of food cannot be evaluated only from the viewpoint of radical scavenging capability.

In the future, it is essential that we isolate and research the substances from antioxidative foods which protect DNA against hydroxyl radical damage.

\section{Acknowledgements}

The authors are grateful to Professor Yukinori Takahashi and Dr Hiroyuki Inagawa (Laboratory of Aquaculture Science, Department of Applied Aquabiology, National Fisheries University) for their instrumental support with this research. Part of this study was presented at the 11th Annual Pukyong National University-National Fisheries University Symposium in Busan, Korea, 2005. This study was supported in part by the research grant of Puffer Fish Project from National Fisheries University in 2005 and 2006.

\section{References}

1. Kehrer JP: Free radicals as mediators of tissue injury and disease. Crit Rev Toxicol 23: 21-48, 1993.

2. Halliwell B, Gutteridge JMC and Aruoma OI: The deoxyribose method: A simple 'test-tube' assay for determination of rate constants for reactions of hydroxyl radicals. Anal Biochem 165: 215-219, 1987.

3. Yamaguchi $\mathrm{T}$, Takamura $\mathrm{H}$, Matoba $\mathrm{T}$ and Terao J: HPLC method for evaluation of the free radical-scavenging activity of foods by using 1,1-diphenyl-2-picrylhydrazyl. Biosci Biotechnol Biochem 62: 1201-1204, 1998.

4. Bonzie IFF and Szeto YT: Total antioxidant capacity of teas by the ferric reducing/antioxidant power assay. J Agric Food Chem 47: 633-636, 1999.

5. Fogliano V, Verde V, Randazzo G and Ritieni A: Method for measuring antioxidant activity and its application to monitoring the antioxidant capacity of wines. J Agric Food Chem 47: 1035-1040, 1999.

6. Liebert M, Licht U, Böhm V and Bitsch R: Antioxidant properties and phenolics content of green and black tea under different brewing conditions. Z Lebensm Unters Forsch A 208: 217-220, 1999.

7. Harada K, Ando M, Kitao S, Sakamoto Y, Kobayashi M and Tamura Y: Measurement of antioxidative capacity of fish sauce using chemiluminescence method. Fish Sci 68 (suppl 2): 1437-1440, 2002.

8. Harada K, Okano C, Kadoguchi H, Okubo Y, Ando M, Kitao S and Tamura Y: Peroxyl radical scavenging capability of fish sauces measured by the chemiluminescence method. Int J Mol Med 12: 621-625, 2003.

9. Harada K: Radical scavenging capability of seafoods using the chemiluminescence and electron spin resonance methods. Int $\mathbf{J}$ Mol Med 14 (suppl 1): 43, 2004.

10. Nagatsuka N, Harada K, Ando M and Nagao K: Effect of soy sauce on the antioxidative capacity of the gelatin gel food 'Nikogori' measured using the chemiluminescence method. Int J Mol Med 16: 427-430, 2005.

11. Tamm C, Hodes ME and Chargaff E: The formation of apurinic acid from the deoxyribonucleic acid of calf thymus. J Biol Chem 195: 49-63, 1952.

12. Greer S and Zamenhof S: Studies on depurination of DNA by heat. J Mol Biol 4: 123-141, 1962.

13. Lindahl T and Nyberg B: Rate of depurination of native deoxyribonucleic acid. Biochemistry 11: 3610-3618, 1972.

14. Sako Y, Uchida A and Kadota H: Injury of deoxyribonucleic acid induced by acid-heating in spores of Bacillus subtilis. Bull Japan Soc Sci Fish 47: 1609-1614, 1981. 
15. Uchida A, Sako Y, Harada K and Kadota H: DNA injury in Bacillus subtilis spores induced by heat treatment. In: Heat Sterilization of Food. Chapter II. Thermomicrobiology. Motohiro T and Hayakawa K (eds). Koseisha-Koseikaku Co., Ltd., Tokyo, pp11-25, 1983.

16. Imamura M, Harada K, Sawada S, Imamura M, Akagi K and Ohnishi T: Damage to DNA purified from the radioresistant prokaryote, Deinococcus radiodurans, by acid heating. Int J Mol Med 3: 391-395, 1999.

17. Ando M, Harada K, Kitao S, Kobayashi M and Tamura Y: Relationship between peroxyl radical scavenging capability measured by the chemiluminescence method and an aminocarbonyl reaction product in soy sauce. Int J Mol Med 12: 923-928, 2003.

18. Nagatsuka N, Harada K, Ando M and Nagao K: Measurement of the radical scavenging activity of chicken jelly soup, a part of the medicated diet, 'Yakuzen', made from gelatin gel food 'Nikogori', using chemiluminescence and electron spin resonance methods. Int J Mol Med 18: 107-111, 2006.

19. Makino Y, Fujisawa H, Okazaki K and Hirata T: Depression effect of foods against DNA damage caused by hydroxyl radical evaluated by biotinylation of apurinic/apyrimidinic sites (In Japanese). Annual Report of Kagawa Prefectural Industrial Technology Center 2: 133-136, 2001.

20. Kubo K, Ide H, Wallace SS and Kow YW: A novel, sensitive, and specific assay for abasic sites, the most commonly produced DNA lesion. Biochemistry 31: 3703-3708, 1992.
21. Ide H, Akamatsu K, Kimura Y, Michiue K, Makino K, Asaeda A, Takamori Y and Kubo K: Synthesis and damage specificity of a novel probe for the detection of abasic sites in DNA. Biochemistry 32: 8276-8283, 1993.

22. Monti $P$, Campomenosi $P$, Ciribilli $Y$, Iannone $R$, Inga $A$, Shah $D$, Scott G, Burns PA, Menichini P, Abbondandolo A, Gold B and Fronza G: Influences of base excision repair defects on the lethality and mutagenicity induced by Me-lex, a sequenceselective N3-adenine methylating agent. J Biol Chem 277: 28663-28668, 2002.

23. Gralnick JA and Downs DM: The YggX protein of Salmonella enterica is involved in Fe(II) trafficking and minimizes the DNA damage caused by hydroxyl radicals. J Biol Chem 278: 20708-20715, 2003.

24. Pippin JW, Durvasula R, Petermann A, Hiromura K, Couser WG and Shankland SJ: DNA damage is a novel response to sublytic complement C5b-9-induced injury in podocytes. J Clin Invest 111: 877-885, 2003.

25. Satoh M, Kashihara N, Fujimoto S, Horike H, Tokura T, Namikoshi T, Sasaki T and Makino H: A novel free radical scavenger, edarabone, protects against cisplatin-induced acute renal damage in vitro and in vivo. J Pharmacol Exp Ther 305: 1183-1190, 2003.

26. Endres M, Ahmadi M, Kruman I, Biniszkiewicz D, Meisel A and Gertz K: Folate deficiency increases postischemic brain injury. Stroke 36: 321-325, 2005. 